\title{
Monitoring and assessment of the state of the atmosphere over the Yenisei riverbed using drone
}

\author{
Oleg E. Yakubailik ${ }^{1}$, Alexey V. Tokarev ${ }^{1}$, Alexey A. Kadochnikov ${ }^{1}$, \\ Valery V. Zavoruev ${ }^{1}$, Konstantin V. Krasnoshchekov ${ }^{2}$ and Alexander V. Dergunov ${ }^{2}$ \\ ${ }^{1}$ Institute of Computational Modelling SB RAS, Krasnoyarsk, Russia \\ ${ }^{2}$ Federal Research Center Krasnoyarsk Science Center SB RAS, Krasnoyarsk, Russia
}

\begin{abstract}
The article is devoted to studying the characteristics of the atmosphere over the Yenisei riverbed with the help of a drone. We develop special mounted measuring equipment for the drone for experimental observations. Designed equipment was used to measure weather parameters and atmospheric pollution from autumn 2020 to summer 2021. More than 50 drone flights were performed during this time. The experiments obtained data from measurements of temperature, relative humidity, and $\mathrm{PM}_{25}$ concentration at different heights above the riverbed. At the same time, no quasi-stationary gradients of meteorological quantities predicted in several publications were found.
\end{abstract}

\section{Keywords}

Temperature inversion, unfavorable meteorological conditions, $\mathrm{PM}_{25}$, GFS, air pollution, Krasnoyarsk.

\section{Introduction}

The temperature regime of rivers in the lower reaches changes after constructing a hydroelectric power station (HPP). The most significant change in the regime occurs when creating highpressure hydroelectric power plants [1].

The nature of thermal changes mainly depends on the depth, volume, area of the water mirror, the flow rate of the reservoir, and the climate of the surrounding area. The depth of the water intake holes greatly influences the water temperature in the lower stream [2]. As a result of creating a hydroelectric power station in the lower reaches, the water temperature decreases in summer and increases in autumn and winter. Therefore, on some rivers, there is a non-freezing ice hole all winter. The longest polynya was formed on the Yenisei in the lower reaches of the Krasnoyarsk hydroelectric power station. Depending on winter conditions, the length of the polynya varies from 105 to $315 \mathrm{~km}$ [3].

The administrative borders of Krasnoyarsk are located in the lower reaches of the Krasnoyarsk hydroelectric power station at a distance of 30-60 km from the dam. The width of the Yenisei riverbed in the city varies from 570 to $1800 \mathrm{~m}$. The approximate area of the Yenisei River water

SDM-2021: All-Russian conference, August 24-27, 2021, Novosibirsk, Russia

Ð oleg@icm.krasn.ru (O.E. Yakubailik); tav@icm.krasn.ru (A.V. Tokarev); scorant@icm.krasn.ru

(A. A. Kadochnikov); valzav@icm.krasn.ru (V.V. Zavoruev); krasko@icm.krasn.ru (K. V. Krasnoshchekov);

alexdergunov@icm.krasn.ru (A.V. Dergunov)

(D) 0000-0002-2668-4776 (O.E. Yakubailik); 0000-0002-9997-9065 (A. V. Tokarev); 0000-0003-0965-3609

(A. A. Kadochnikov)

(c) (1) $\odot 2021$ Copyright for this paper by its authors. Use permitted under Creative Commons License Attribution 4.0 International (CC BY 4.0).

CEUR Workshop Proceedings (CEUR-WS.org) 
area is about $8 \%$ of the city's total area. Thus, a unique situation has formed in Siberia, when there is a non-freezing water surface in winter with an area of up to $30 \mathrm{~km}^{2}$ in the center of a million-strong city. At the same time, the following fact should be emphasized: since the commissioning of the Krasnoyarsk HPP until 2019, experimental studies of the state of atmospheric air over the Yenisei riverbed have not been conducted.

In 2017, a scientific article was published on the modeling of atmospheric processes occurring over the river and the city's territory [4]. In this work, a scheme of the formation of wind flows near the Yenisei riverbed and the distribution of air temperature over the water area of the river was presented. Calculations have shown that the temperature gradient is formed from the water surface to a height of about 500-600 m, and in the horizontal direction, the temperature difference can reach $6{ }^{\circ} \mathrm{C}$. In addition, from the analysis of the data presented in the article, there is a humidity gradient over the Yenisei river. Moreover, the humidity gradient must be recorded during horizontal (perpendicular to the river flow) monitoring at 50-300 meters altitudes.

In connection with the above, the purpose of this work was to develop methods and equipment for studying the state of the atmosphere over the Yenisei riverbed in the winter conditions of Siberia. The working hypothesis was that there are temperature and humidity gradients over the Yenisei River. These factors, in turn, affect the particulate matter distribution in the surface layer of the atmosphere.

\section{Materials and methods}

Measurements of the atmosphere's main characteristics over the Yenisei River's water area were carried out using mounted equipment installed on an unmanned aerial vehicle (UAV).

The analysis of the UAV market showed that the expected operating conditions are best met by the DJI Matrice $210 \mathrm{~V} 2$ industrial drone. This is a universal platform that is characterized by strength and ease of use in various industries. The V2 series improvements cover control systems, flight characteristics, as well as flight and data safety.

For a visual assessment of the state of the atmosphere (fog, etc.), the DJI Matrice $210 \mathrm{~V} 2$ drone is equipped with a camera on a gyro-stabilized platform. The DJI Zenmuse X4S lens camera allows frame-by-frame/series/interval photo/video shooting with a resolution of up to $5472 \times 3648(20 \mathrm{MP})$.

Measurements of temperature, relative humidity, atmospheric pressure, the $\mathrm{PM}_{25}$ concentration were carried out using mounted measuring equipment made of various electronic components (sensors, controllers, etc.), like a "LEGO constructor". Some of the elements were printed using a 3d-printer (Figure 1). The authors have experience in such developments; a similar device for stationary placement was previously implemented [5].

The sensors are duplicated, followed by averaging the measured values. The developed equipment for measuring the state of the atmosphere is based on the ESP32 microcontroller and the following sensors.

- Bosch BME280 is a combined humidity, temperature, and atmospheric pressure sensor module with a digital interface. Measurement accuracy of relative humidity: $\pm 3 \% \mathrm{RH}$, pressure: $\pm 1.0 \mathrm{hPa}$, temperature: $\pm 1.0^{\circ} \mathrm{C}$. Operating temperature range: $-40 \ldots 85^{\circ} \mathrm{C}$, pressure: $300 \ldots 1100 \mathrm{hPa}$. 
- Sensirion SHT31 is a high-precision digital temperature and humidity sensor. The chip is well calibrated and linearized. The typical accuracy of this module is $\pm 2 \% \mathrm{RH}$ for relative humidity and $\pm 0.3{ }^{\circ} \mathrm{C}$ for temperature. Operating temperature range: $-40 \ldots 125^{\circ} \mathrm{C}$.

- Plantower PMS7003 is a sensor for measuring the concentration of particulate matter $\left(\mathrm{PM}_{1.0}, \mathrm{PM}_{25}, \mathrm{PM}_{10}\right)$. The sensor accuracy is within $\pm 10 \mathrm{mg} / \mathrm{m}^{3}$ at concentrations up to $100 \mathrm{mg} / \mathrm{m}^{3}$ and $\pm 10 \%$ at concentrations over $100 \mathrm{mg} / \mathrm{m}^{3}$. Operating temperature range: $-10 \ldots 60{ }^{\circ} \mathrm{C}$.

- uBlox Neo 8M-GPS/GLONASS module with an active antenna.

The mounted unit uses sensors: $1 \times$ BME $280,2 \times$ SHT31, $2 \times$ PMS7003, $1 \times$ uBlox Neo $8 \mathrm{M}$.

The GPS module provides accurate data binding by time.

The registered indicators are recorded on a microSD card with an interval of 1 second in CSV format exchange files. For convenience, an import module has been developed that provides loading data from exchange files from the drone's mounted measuring equipment into the system. In the user interface, the operator specifies the device from which the results were obtained, the route of the flight performed, the name, a description of the conditions and features of the mission, and also specifies a data file to download. As a result, the data falls into a single flight database for storage and analytical processing.

The reliability of the measuring instruments used is ensured by calibration of the equipment according to reference devices.

The calibration is based on the use of the following measuring equipment and data.

- UAV mounted measuring equipment.

- Air monitoring stations of the air monitoring system of the Krasnoyarsk Scientific Center SB RAS. CityAir certified air monitoring stations are used as the basic equipment in this system of the KSC SB RAS [6].

- Data of the Regional departmental information and analytical data system on the state of the environment of the Krasnoyarsk Territory. This system developed by the Ministry of Ecology and Rational Nature Management of the Krasnoyarsk Territory.

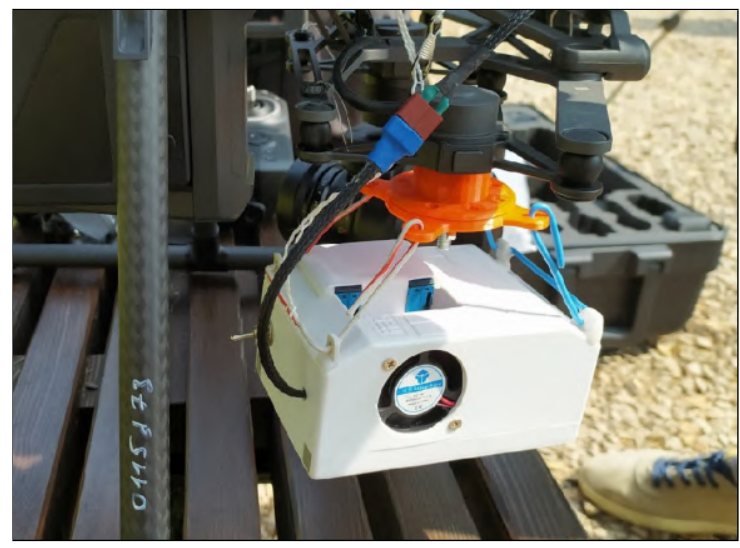

Figure 1: Unmanned aerial vehicle mounted measuring equipment. 
The measurements of the drone and CityAir stations were processed using descriptive statistics in the Microsoft Excel program. It was found that three temperature sensors and three relative humidity sensors installed in the drone's mounted measuring equipment correctly measure the corresponding meteorological parameters. The readings of two $\mathrm{PM}_{25}$ concentration sensors installed in the mounted unit should be divided by a correction factor of 8.3.

Thus, the comparability of the data recorded by all three listed sources of information was ensured.

\section{Results and discussion}

The manufacturer of drone does not recommend operating the DJI Matrice 210 V2 model at temperatures below $-20^{\circ} \mathrm{C}$. This recommendation was strictly observed when monitoring the water area of the Yenisei River.

We performed about 50 horizontal flights from September 14, 2020, to July 9, 2021, at 1070 meters altitudes. Typical results of measurements of temperature, relative humidity, and $\mathrm{PM}_{25}$ concentration obtained during one of these flights in the vicinity of the village of Peschanka (Krasnoyarsk) are shown in Figures 2-4.

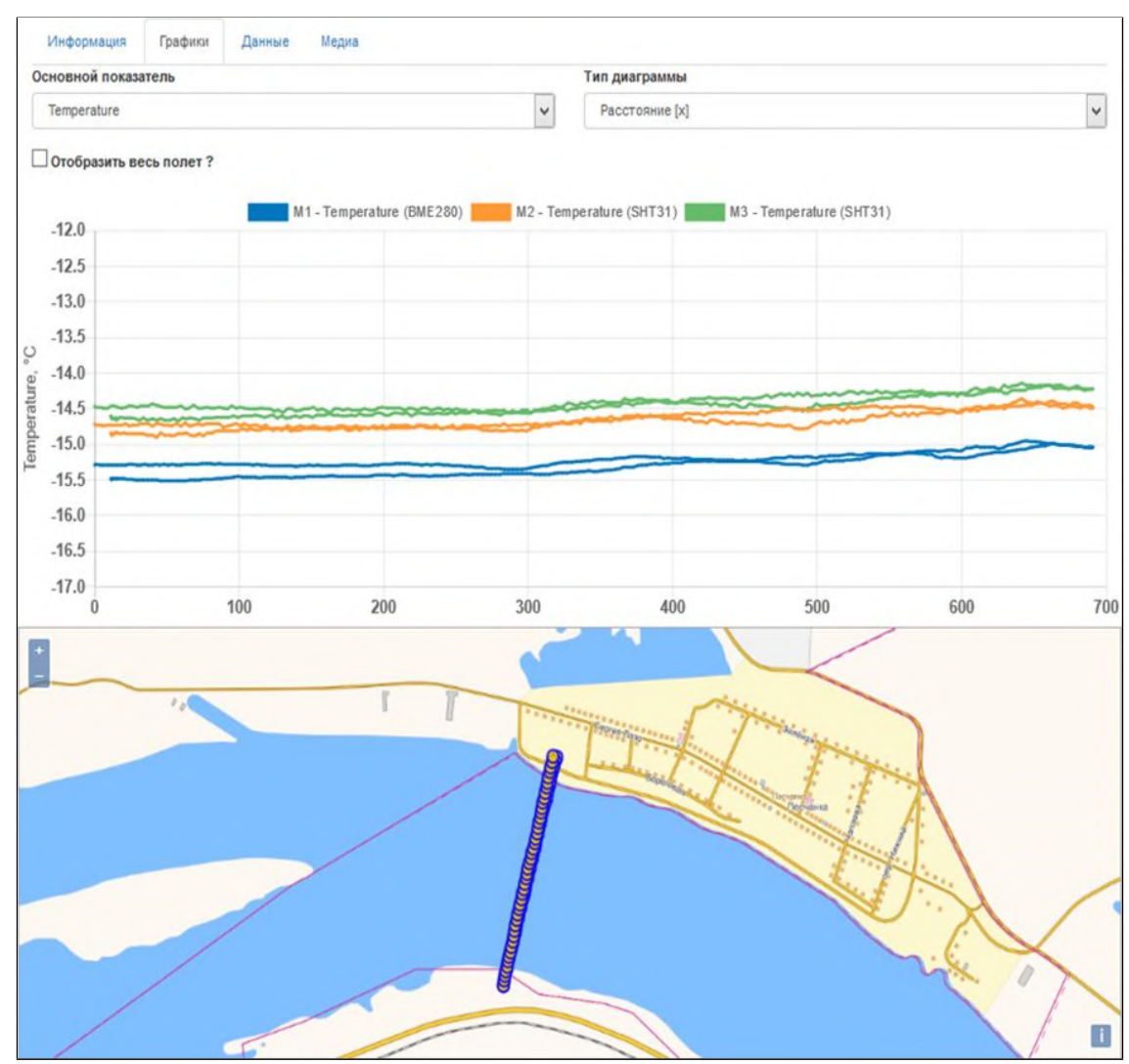

Figure 2: Flight over the Yenisei on December 16, 2020, speed $3 \mathrm{~m} / \mathrm{s}$, temperature registration period 16:18-16:26 local time. 


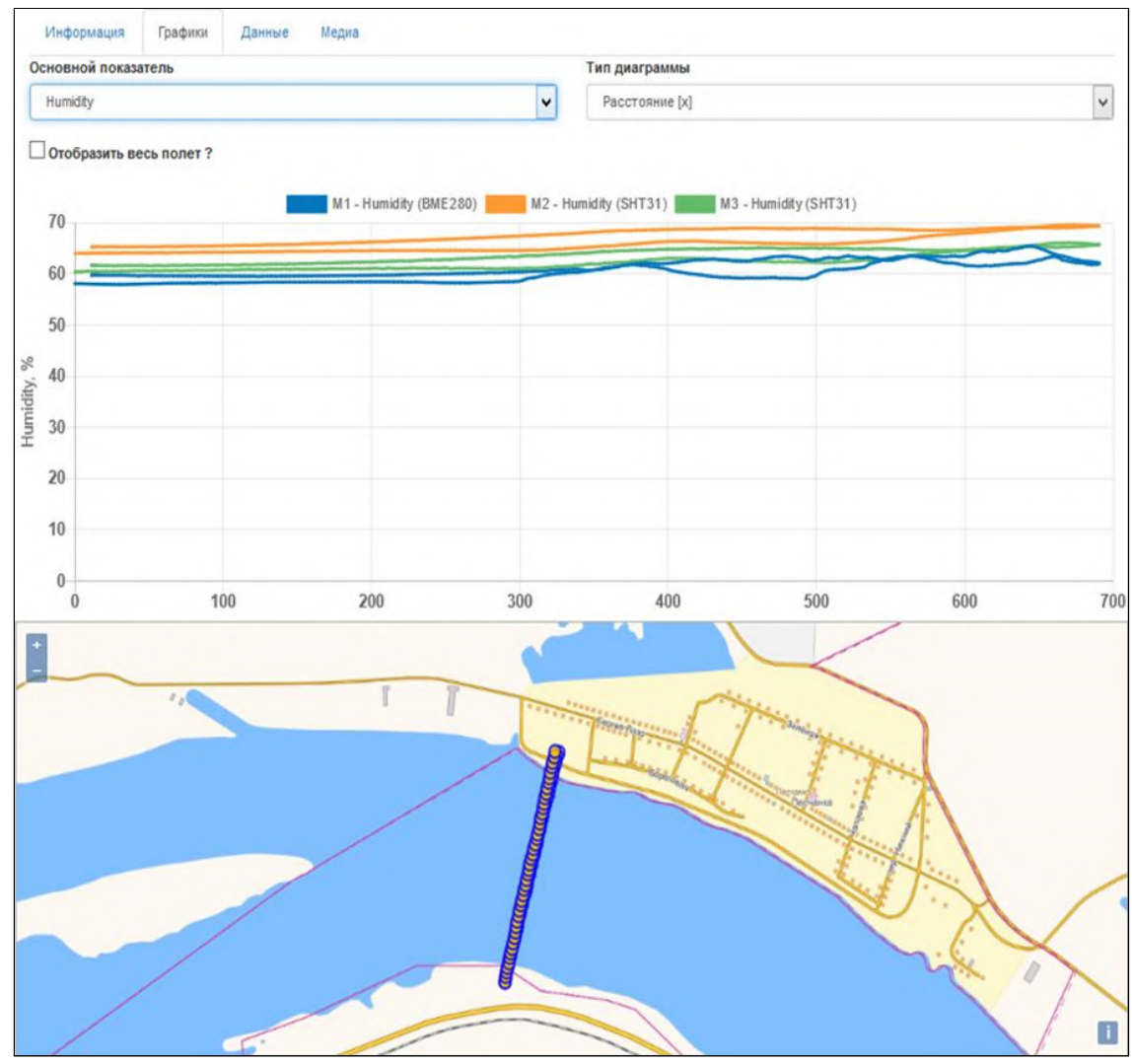

Figure 3: Flight over the Yenisei on December 16, 2020, speed $3 \mathrm{~m} / \mathrm{s}$, the period of registration of relative humidity is 16:18-16:26 local time.

As a result of statistical analysis of the data obtained during the drone's flight on December 16, 2020, the following was established.

The average value of the air temperature during the flight, calculated from the measurement data of three sensors, was minus $14.79 \pm 0.01{ }^{\circ} \mathrm{C}$, the minimum value was $15.02{ }^{\circ} \mathrm{C}$, and the maximum value was $14.49^{\circ} \mathrm{C}$. Considering the accuracy of the sensors, it can be concluded that there is no temperature gradient in the area of the Yenisei River water area.

The average value of the relative humidity of the air during the flight, calculated from the measurement data of three sensors, was $64.6 \pm 0.2 \%$, the minimum value was $60.0 \%$, and the maximum value was $67.8 \%$. Considering the accuracy of the sensors, it can be concluded that there is no gradient of relative humidity in the area of the Yenisei River water area.

The average value of the concentration of suspended particles of $\mathrm{PM}_{25}$ during the flight, calculated from the measurement data of two sensors and taking into account the correction factor, was $4.3 \pm 0.3 \mathrm{mg} / \mathrm{m}^{3}$, the minimum value is $-1.5 \mathrm{mg} / \mathrm{m}^{3}$, and the maximum value is $18.0 \mathrm{mg} / \mathrm{m}^{3}$. Formally, we can talk about an inhomogeneous distribution of $\mathrm{PM}_{25}$ over the Yenisei riverbed. However, the data analysis shows that a jump in the concentration of $\mathrm{PM}_{25}$ is observed when the drone flies from the left bank to the right bank, and when flying in the opposite direction, such a jump is not recorded. This is probably due to the influence of 


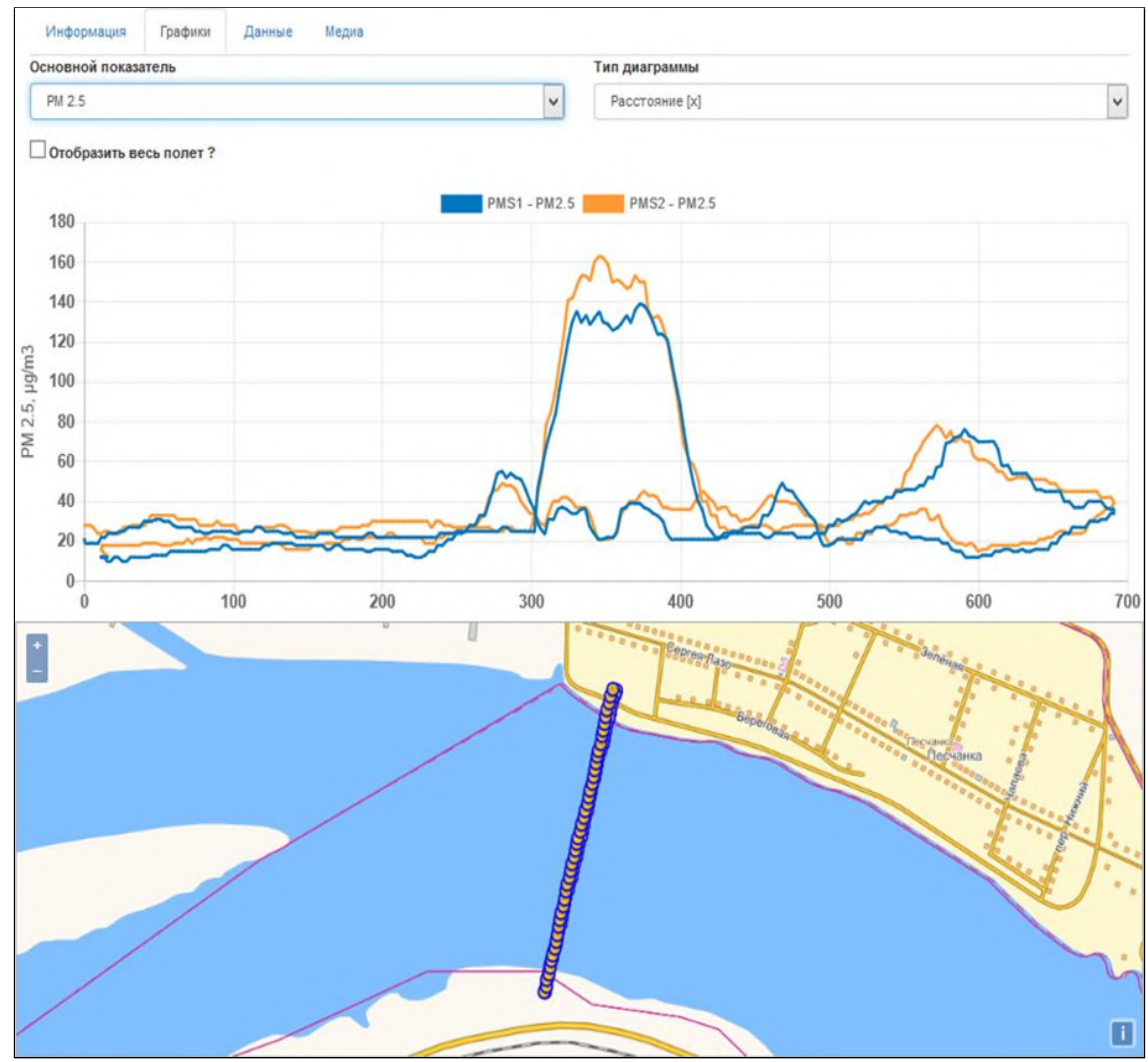

Figure 4: Flight over the Yenisei on December 16, 2020, speed $3 \mathrm{~m} / \mathrm{s}$, the registration period of the concentration of $\mathrm{PM}_{25}$ is 16:18-16:26 local time. The $\mathrm{PM}_{25}$ concentration is presented without taking into account the correction factor.

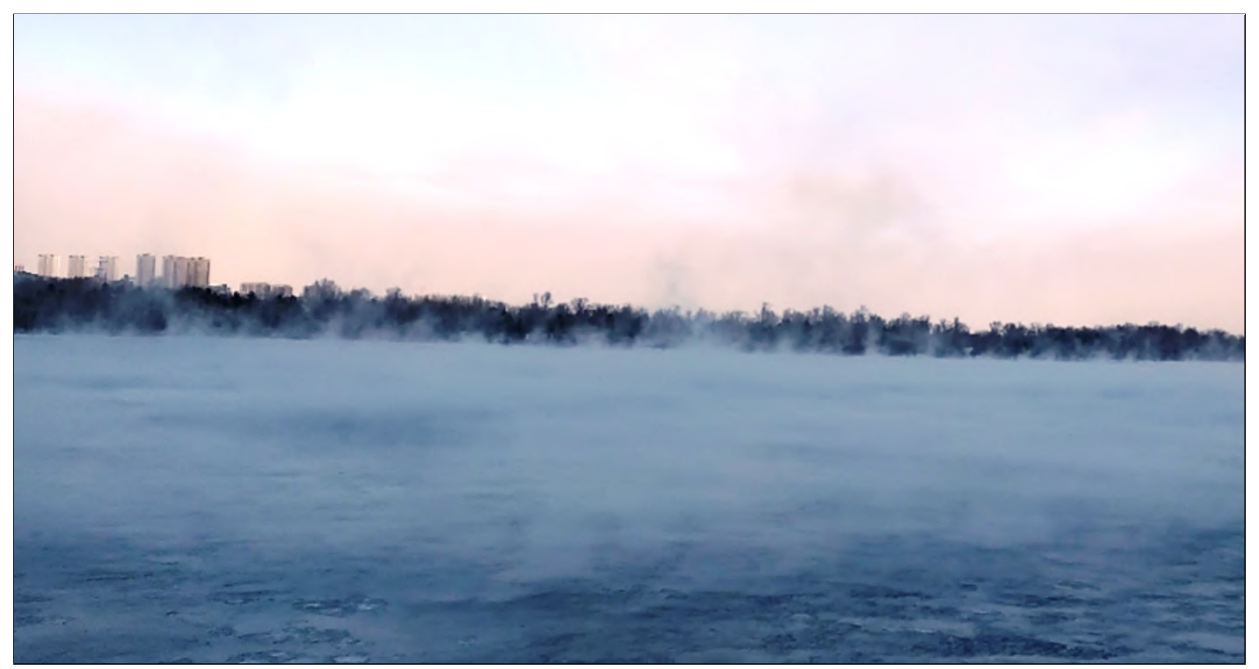

Figure 5: Soaring over the riverbed in winter. 
an aerosol of ascending water vapor, which is formed spontaneously and unevenly over the water area of the river at a negative air temperature and a weak wind (Figure 5). Such weather conditions were observed at the Berezovka monitoring station (located $4 \mathrm{~km}$ from the flight area) on December 19, 2020, from 16 to 17 hours. The wind speed was $0.6 \pm 0.1 \mathrm{~m} / \mathrm{s}$, and the air temperature was minus $15.9 \pm 0.5{ }^{\circ} \mathrm{C}$. Therefore, there is no reason to assert a quasi-stationary gradient of $\mathrm{PM}_{25}$ concentrations over the water area of the Yenisei River.

As a result of analyzing the data of numerous measurements made with the help of a drone at atmospheric air temperatures up to $-20^{\circ} \mathrm{C}$, it was concluded that there are no quasi-stationary gradients of temperature, relative humidity, and $\mathrm{PM}_{25}$ concentration over the Yenisei riverbed.

\section{Conclusions}

Model calculations show that ascending wind flows form over the central part of the Yenisei riverbed in winter [4, 7]. As a consequence of this process, it is assumed that there are gradients of temperature and relative humidity over the water area of the river [4].

Experimental studies performed from September 14, 2020, to July 9, 2021, did not confirm the results of model calculations. The theoretically predicted gradients of meteorological parameters are likely formed over the water area of the river at temperatures below minus $20^{\circ} \mathrm{C}$.

A full-scale study of the regularity of the distribution of temperature, relative humidity, and concentration of suspended particles over the polynya at low temperatures (from -20 to $-40{ }^{\circ} \mathrm{C}$ ) has not yet been performed. The experience of using a drone at low temperatures comparable to those observed in Krasnoyarsk is described in a preprint of an article published in February 2021, prepared by a group of Canadian researchers [8]. This article describes in detail the successful operation of the Matrice 210 RTK drone in low Arctic temperatures. This allows us to hope that the results of model calculations presented in paper [4] can be verified soon.

\section{Acknowledgments}

The authors express their acknowledges to JSC Krasnoyarsk HPP and En+ Group for the financial support of the studies on the state of the atmosphere over the Yenisei riverbed using an unmanned aerial vehicle.

\section{References}

[1] Y. Gottlieb, R. Donchenko, A. Pehovich, I. Sokolov, Ice in reservoirs and lower reaches of hydroelectric power plants, Gidrometeoizdat, Leningrad, 1983.

[2] Y. Gottlieb, V. Zhidkikh, N. Sokolnikov, Thermal regime of reservoirs of hydroelectric power plants, Gidrometeoizdat, Leningrad, 1976.

[3] I. Kosmakov, Thermal and ice regime in the upper and lower reaches of high-pressure hydroelectric power plants on the Yenisei, Claretianum, Krasnoyarsk, 2001. 
[4] M. Hrebtov, K. Hanjalić, Numerical study of winter diurnal convection over the city of krasnoyarsk: Effects of non-freezing river, undulating fog and steam devils, Boundary-Layer Meteorology 163 (2017) 469-495. doi:10.1007/s10546-016-0231-0.

[5] O. Yakubailik, A. Kadochnikov, A. Tokarev, Web geographic information system and the hardware and software ensuring rapid assessment of air pollution, Optoelectronics, Instrumentation and Data Processing 54 (2018) 243-249. doi:10 .3103/S8756699018030056.

[6] V. Zavoruev, E. Zavorueva, A. Kadochnikov, A. Tokarev, O. Yakubailik, Assessment of the possibility of using CityAir air monitoring station in environmental engineering, IOP Conference Series: Materials Science and Engineering 537 (2019) 062053. doi:10.1088/ 1757-899X/537/6/062053.

[7] A. Romanov, B. Gusev, E. Leonenko, A. Tamarovskaya, A. Vasiliev, N. Zaytcev, I. Philippov, Graz lagrangian model (gral) for pollutants tracking and estimating sources partial contributions to atmospheric pollution in highly urbanized areas, Atmosphere 11 (2020) 1-26. doi:10.3390/atmos11121375.

[8] A. Tikhomirov, G. Lesins, J. Drummond, Drone measurements of surface-based winter temperature inversions in the high arctic at eureka, Atmospheric Measurement Techniques (2021). doi:10.5194/amt-2020-515. 